\title{
ARTÍCULOS
}

\section{LA TRAYECTORIA DE PEDRO JOSÉ AGRELO A TRAVÉS DE LA CIRCULACIÓN REGIONAL Y LA DINÁMICA CIUDAD-PUERTO.}

\author{
Ariel Alberto Eiris \\ Universidad Católica Argentina \\ eirisariel@gmail.com
}

Resumen: Las dinámicas ciudades-puerto implican procesos de transformaciones sociales, económicas y políticas que influyen sobre los diversos actores sociales. El estudio de la trayectoria de uno de esos actores, vinculados a la actividad gubernamental y cultural permite comprender la forma en que se dieron este tipo de procesos. Para ello se tomará el caso del letrado Pedro José Agrelo, quien facilitará el estudio de las transformaciones de eje de circulaciones culturales y espacios políticos en función de los desarrollos portuarios regionales.

Palabras clave: Ciudades-puerto, Pedro José Agrelo, Chuquisaca, Buenos Aires, Entre Ríos.

Tittle: THE PATH OF PEDRO JOSÉ AGRELO THROUGH REGIONAL CIRCULATION AND THE DYNAMIC CITY-PORT.

Abstract: The dynamic port-cities involve processes of social, economic and political transformations that influence the various social actors. The study of the trajectory of one of these actors, linked to the governmental and cultural activity allows to understand the way in which this type of processes were given. For this, the case of the lawyer Pedro Jose Agrelo will be taken, who will facilitate the study of transformations of the axis of cultural movements and political spaces in function of regional port developments.

Keywords: Cities-port, Pedro José Agrelo, Chuquisaca, Buenos Aires, Entre Ríos.

\section{Introducción}

La trayectoria política y jurídica de Pedro José Agrelo (1776-1846) se desarrolló en el Río de la Plata, a través de una relevante actividad jurídico-política. La misma se realizó en diversas regiones como Buenos Aires, el Alto Perú y Entre Ríos. Tras un rápido ingreso y ascenso en la administración borbónica en el Alto Perú, integró los sectores revolucionarios de Buenos Aires a partir de principios de 1811. ${ }^{1}$ Desde allí se desenvolvió como periodista, integrante de la Cámara de Apelaciones, fiscal

\footnotetext{
${ }^{1}$ El único trabajo específico sobre la trayectoria de Agrelo es el que refiere a dicho momento. Ver: CORREA LUNA, Carlos. La iniciación revolucionaria: El caso del doctor Agrelo, Buenos Aires, 1915.
}

Recibido: 22-06-2020

Aceptado: $10-07-2020$

Cómo citar este artículo: EIRIS, Ariel Alberto. La trayectoria de Pedro José Agrelo a través de la circulación regional y la dinámica ciudad-puerto. Naveg@mérica. Revista electrónica editada por la Asociación Española de Americanistas [en línea]. 2020, n. 25. Disponible en: <http://revistas.um.es/navegamerica>. [Consulta: Fecha de consulta]. ISSN 1989-211X. 
del juicio contra Martín de Álzaga (1812) y miembro de la Logia Lautaro. Con posterioridad a dicho año, fue diputado y presidente de la Asamblea del Año XIII, donde promovió la acuñación de moneda soberana y colaboró en la presentación de un proyecto de constitución. Allegado a Carlos de Alvear, conspiró contra el gobierno directorial de Juan Martín de Pueyrredón lo que le valió el exilio en Estados Unidos en 1817 donde se vinculó con pensadores federales norteamericanos. En 1820 participó de los gobiernos débiles de Buenos Aires, donde promovió el "motín del Cabildo" del $1^{\circ}$ de octubre. Exiliado en Entre Ríos colaboró en la redacción de su Estatuto Provincial en 1822. Regresó a Buenos Aires donde fue docente en la Universidad de Buenos Aires y Fiscal de Estado desde donde redactó el Memorial Ajustado. Allegado a los federales cismáticos, fue exiliado durante el segundo gobierno de Rosas e integró en Montevideo la Convención Argentina.

Su importancia en el período estudiado se evidencia en las referencias realizadas hacia su figura en investigaciones centrales sobre cuestiones de relevancia para las ciencias sociales como la organización jurídico-institucional, el accionar del periodismo, las políticas secularistas, y la actividad política en general ${ }^{2}$. Todas estas producciones señalan su activa y significativa presencia en los acontecimientos claves de la época, pero sin detenerse en la trayectoria del letrado, ni en su posición conflictiva ante los cambios en las estructuras jurídico-políticas.

Por ello, el presente trabajo se inscribe dentro del marco general de la investigación sobre su trayectoria político-jurídica, que permite desentrañar las formas en que el letrado en cuestión se vinculó a los sucesivos gobiernos y actuó en función de ellos dando aportes administrativos y teóricos según las necesidades coyunturales. Este artículo se centrará exclusivamente en la relación mantenida por Agrelo con respecto a las ciudades-puerto y ejes productivos en donde se desempeñó, mediante su participación en el desarrollo de espacios culturales locales.

Para ello, se abordará como caso de estudio el desempeño del letrado Agrelo, sobre cuya trayectoria y actividad como agente cultural circulante por los ejes productivos y portuarios rioplatenses, puede mostrar aspectos particulares sobre el

\footnotetext{
${ }^{2}$ Como ejemplos de trabajos que consideren de manera no central, pero que denotan la importancia de Agrelo y su presencia en estos espacios se puede consultar: LEVENE, Ricardo. Ensayo histórico sobre la Revolución de Mayo y Mariano Moreno. Buenos Aires: Facultad de Derecho y Ciencias Sociales, 1921; RAVIGNANI, Emilio. Historia constitucional de la República Argentina. Vol. 2. Buenos Aires: Peuser, 1927; FÚRLONG, Guillermo. Nacimiento y desarrollo de la filosofía en el Río de la Plata, 1536-1810. Buenos Aires: Kraft, 1952; TAU ANZOÁTEGUI, Víctor. Formación del Estado Federal Argentino, 1829-1852: la intervención del gobierno de Buenos Aires en los asuntos nacionales. Buenos Aires: Editorial Perrot, 1965; ZORRAQUíN BECÚ, Ricardo. Historia del derecho argentino. Tomo II (1810-1969). Buenos Aires: Editorial Perrot, 1966; HALPERÍN DONGHI, Tulio. Revolución y guerra: Formación de una élite dirigente en la Argentina criolla. Buenos Aires: Siglo XXI, 1972; BOTANA, Natalio. La Libertad Política y su Historia. Buenos Aires: Ed. Sudamericana, 1991; CHIARAMONTE, José Carlos. Nación y Estado en Iberoamérica: El lenguaje político en los tiempos de las independencias. Buenos Aires: Sudamericana, 2004; DE MARCO, Miguel Ángel. Historia del periodismo argentino. Buenos Aires: Educa, 2006; TERNAVASIO, Marcela. Gobernar la revolución. Poderes en disputa en el Río de la Plata (1810-1816). Buenos Aires: Siglo XXI, 2007; GOLDMAN, Noemí, y PASINO, Alejandra. Opinión pública. En: GOLDMAN, Noemí (ed.). Lenguaje y revolución: conceptos políticos clave en el Río de la Plata, 1780-1850. Buenos Aires: Prometeo, 2008.
} 
desarrollo de esta dinámica entre fines del siglo XVIII y principios del XIX. Esto se debe a las significativas transformaciones políticas, institucionales, económicas, sociales y culturales producidas en la región por esos años y la permanente presencia política y cultural que el letrado en cuestión tuvo entre los espacios geográficos constituidos por diferentes ejes portuarios o productivos regionales.

Su trayectoria y la forma en que circuló en la región, sin dejar de integrar la dirigencia política local, plantea el problema al respecto de si existió y de qué forma, una relación entre su actividad política y los cambios de primacía de las ciudadespuertos y ejes productivos del momento. Se entiende que esta vinculación existió e implicó cambios en las condiciones económicas y políticas regionales, que se materializaron en la circulación de agentes letrados, como el caso de Agrelo, que requerían de un espacio institucional para realizar su profesión, a la vez que contribuían a dichas dinámicas. Por eso, la hipótesis del trabajo es que la trayectoria de Agrelo implicó la circulación del letrado por diferentes ejes productivos, en función de su primacía política en momentos específicos.

Para ahondar en esta problemática, es necesario considerar las características particulares de las dinámicas productivas y portuarias, junto con la forma en que ésta actúa sobre la actividad cultural regional. Las ciudades-puerto se desempeñan como centros de recepción cultural y material al representar ejes de circulación empalmados con otras áreas productivas. Gracias a la configuración del espacio de influencia, la ciudad-puerto logra operar no solamente en el plano económico y social, sino también en el político y en la transferencia cultural. Eso facilita que, según el grado de desarrollo, la ciudad-puerto pueda convertirse en un eje de atracción y concentración de actores sociales vinculados con la actividad cultural y la administración gubernamental. Un desarrollo sostenido del mismo, permite que se dispongan de los recursos materiales y financieros necesarios para sostener instituciones culturales y educativas, que permitan la formación de agentes que puedan contribuir al crecimiento de la ciudad-puerto mediante su desempeño como funcionarios.

Por estas cuestiones, una ciudad-puerto se complementa con otras y sus respectivas regiones de alcance, donde pueden incluso superponerse áreas de influencia, constituyendo así un "espacio portuario" en el interior de un territorio, gracias a las conexiones mantenidas, más allá de la cuestión fluvial. Eso se debe en particular a la etapa de desarrollo en que se encuentre los espacios de interface productiva, dada la expansión de su influencia mercantil por un hinterland propio ${ }^{3}$. Así, se evidencian en el Río de la Plata ejes como Chuquisaca, Córdoba, Buenos Aires, Montevideo y más adelante el Litoral. Los cambios en la política y la proyección económica de cada territorio, implicarán entonces mutaciones en la atracción de funcionarios de gobierno y figuras de la cultura, como lo era Agrelo.

\footnotetext{
${ }^{3}$ Hoyle sintetizó un modelo de desarrollo por etapas de la relación espacial entre el puerto y la ciudad. Establece etapas caracterizadas por formas diferentes de asociación y separación. Su propuesta en la base de la Escuela de Southampton, de gran presencia actual en las investigaciones portuarias. Consultar: HOYLE, Brian. The port-city interface: Trends, problems and examples. Geoforum. 1989, vol. 20, n. 20, pp. 429-436.
} 
En ese marco, es importante considerar el concepto de "letrado", el cual hacía referencia en su época tanto al alfabetizado, como "al que trabaja con las letras" mediante un desempeño intelectual en su sentido amplio ${ }^{4}$. Por tal cuestión el término alude a su especialidad en la cultura escrita fundamentada en amplias y variadas áreas del conocimiento. Su capacidad erudita quedaba estrechamente vinculada al conocimiento del funcionamiento jurídico del cuerpo político y a sus necesidades. Por todo ello, el letrado era un "hombre de saber", de erudición general que durante el período estudiado se encontraba preparado para responder a necesidades del gobierno, por lo que su desempeño no podía quedar aislado de la actividad política. Ello implicaba que su formación y el desarrollo de su actividad estuvieran especialmente vinculados con las regiones de mayor desarrollo administrativo y estatal. Los letrados como Agrelo actuaban en función del gobierno, desempeñándose en la administración de justicia, interviniendo en la conducción política, participando de proyectos jurídicos y formando a otros letrados. Ello se daba desde el sistema borbónico y continuó posteriormente a la Revolución. Ello ocurría cuando la justicia no estaba conceptualmente separada del gobierno, por lo que ésta operaba como expresión del orden político ${ }^{6}$.

En ese marco analítico podemos entonces comprender la relación existente entre la necesidad de un letrado por actuar bajo la égida de un gobierno específico, con respecto al espacio socio-político articulado en torno a los ejes portuarios y productivos que fuera capaz de darle al letrado ese espacio de actuación. Comprender la forma en la que esta lógica fue desarrollada en el Río de la Plata a fines del siglo XVIII y principios del XIX, permite abordar el desarrollo de la problemática desde una perspectiva histórica que pueda reconstruir las características y los cambios de ejes sufridos en aquel período de significativos cambios políticos para la región. En ese sentido, la trayectoria de Agrelo es un caso que facilitará abordar la cuestión a partir de los ejes regionales en los que actuó, durante el Virreinato del Río de la Plata y luego del proceso revolucionario iniciado en 1810 .

\footnotetext{
${ }^{4}$ El letrado queda entonces asociado al concepto de intelectual solamente en cuanto "experto en el manejo de los recursos simbólicos", es decir persona especializada en el uso de sus capacidades intelectuales al momento de estudiar la realidad y elaborar representaciones y explicaciones que dieran sentido a sus percepciones. Es entonces un hacedor de cultura escrita. Ver: MYERS, Jorge, EI letrado patriota: los hombres de las letras hispanoamericanos en la encrucijada del colapso del imperio español en América. en: ALTAMIRANO, Carlos y MYERS, Jorge (coords.). Historia de los intelectuales en América Latina. Vol I: La ciudad letrada, de la conquista al modernismo. Buenos Aires: Katz, 2008, pp. 121-144.

${ }^{5}$ Conf. MAZÍN, Óscar. Gentes de saber en los virreinatos de Hispanoamérica (siglos XVI al XVIII. En: ALTAMIRANO, Carlos y MYERS, Jorge (coords.). Historia de los intelectuales... Op. cit., pp. 53-78.

${ }^{6}$ GARRIGA, Carlos. Orden jurídico y poder político en antiguo régimen: la tradición jurisdiccional. En: GARRIGA, Carlos y LORENTE SARINENA, Marta. Cádiz 1812. La constitución jurisdiccional. Madrid: CEPC, 2007, p. 20. Sobre la lenta separación de la justicia respecto al gobierno, consultar: BARRIERA, Darío. Del gobierno de los jueces a la desjudicialización del gobierno. Desenredos en la trenza de la cultura jurisdiccional en el Río de la Plata (Santa Fe, 1780-1860). En: AGÜERO, A.; SLEMIAN A. y FERNÁNDEZ DE SOTELO, Rafael Diego (coords.). Jurisdicciones, Soberanías, Administraciones: Configuración de los espacios políticos en la construcción de los estados nacionales en Iberoamérica. Córdoba: Editorial de la Universidad Nacional de Córdoba; México: El Colegio de México, 2018, pp. 371-406.
} 
Por todo ello, nuestros objetivos específicos serán entonces comprender la forma en que el desarrollo de una ciudad-puerto influyó en la configuración del espacio de circulación cultural a la que pertenecía Agrelo; analizar cómo las principales ciudades-puerto o ejes productivos constituyeron áreas de concentración de la dirigencia política, lo que implicó el desplazamiento de Agrelo. Las fuentes trabajadas son las memorias publicadas e inéditas de Agrelo, sumado a documentos de gobierno y correspondencia epistolar entre Agrelo y otros miembros de la dirigencia política local, como Bernardino Rivadavia.

Para analizar esta cuestión, el trabajo partirá de la formación educativa de Agrelo en función de su ubicación en Buenos Aires y las condiciones socioeconómicas de su espacio. Luego se abordará el eje productivo de Chuquisaca, junto con la importancia y la impronta educativa que su Universidad tenía sobre el área del Río de la Plata. A partir de entonces podrá vislumbrarse el quiebre generado en 1810 y los cambios fiscales, políticos y de circulación de agentes socioculturales que causaría el desplazamiento de letrados como Agrelo. Esa cuestión será nuevamente redefinida con la crisis de 1820 y el surgimiento de nuevos ejes portuarios y productivos como Entre Ríos. Allí se podrá ver la tensión existente entre Buenos Aires y el Litoral y cómo ello afectó a la ubicación de agentes políticosculturales como Agrelo, hasta culminar con una nueva hegemonía económica de Buenos Aires a partir de inicios de la década de 1820.

\section{Buenos Aires como espacio portuario y cultural creciente durante la infancia de Agrelo}

La designación de Buenos Aires como capital virreinal desde 1776, implicó transformaciones profundas en la dinámica social y económica de la ciudad. Con anterioridad, su puerto había sido favorable al contrabando dado su alejamiento de los ejes comerciales y distributivos dentro del monopolio español. Sin embargo, su nueva centralidad política y el establecimiento del Tratado de Libre Comercio (1778) permitieron la conformación de la aduana de Buenos Aires que materializó el auge comercial en el que entró la región. La organización del nuevo virreinato requería de cambios en el sistema institucional y burocrático, lo que facilitó el desarrollo de una nueva elite letrada vinculada con aquella actividad, a la par del crecimiento de aquella vinculada a las redes comerciales creadas ${ }^{7}$.

Con este desarrollo de Buenos Aires, el nuevo Virreinato adquirió dos ejes de producción fiscal, la cuenca del litoral centrada en las exportaciones del nuevo puerto habilitado, y el tradicional eje regional de Potosí, donde su mina y producción de plata alimentaba el comercio alto peruano ${ }^{8}$. Hasta entonces, esta zona había sido centro absoluto del desarrollo regional, ante la restricción comercial del litoral, motivo por el cual actuaba como un "eje productivo" en cuanto su circulación mercantil, aunque técnicamente no tuviera salida fluvial ni portuaria. El crecimiento de Buenos

\footnotetext{
${ }^{7}$ Al respect, consular: SOCOLOW, Susana. The Bureaucrats of Buenos Aires, 1769-1810: Amor Al Real Servicio. London: Duke University Press, 1987.

${ }^{8}$ Al respecto, consultar TANDETER, Enrique. Coacción y Mercado: la Minería de la Plata en el Potosí Colonial, 1692-1826. Buenos Aires: Sudamericana, 1992; y CORTÉS CONDE, Roberto. La economía argentina en el largo plazo. Siglos XIX y XX. Buenos Aires: Sudamericana, 1997, pp.79-81.
} 
Aires tendió a equilibrar el desarrollo entre ambas regiones, aunque Potosí permanecía como fuente fiscal fundamental para la región del Río de la Plata. Ésta última, gracias a la liberalización de los puertos, se constituyó progresivamente en un espacio productivo articulado y creciente que fortaleció las identidades regionales y configuró el "complejo portuario rioplatense" . Ello fue atractivo para españoles que vieron la conveniencia de establecerse en Buenos Aires al poder crecer en su actividad económica. Tal sería el caso del peninsular Inocencio Agrelo, quien vendría como mercader a la ciudad y se casaría con una mujer de la elite local, Beatriz Moreyra. Su hijo primogénito sería Pedro José Agrelo, nacido en 1776, a la par de la constitución del nuevo Virreinato.

La familia Agrelo logró criar a su hijo en un marco social de cuidados y de buen acceso a recursos básicos. Esto se daba a pesar de los ingresos más austeros de Inocencio, en comparación con la familia de su esposa. A pesar de ello, ambos se mantenían en la condición de "gente decente", esto significaba -dentro de la sociedad americana- que eran considerados jurídicamente como españoles-criollos, el padre de familia era propietario y poseía voz y voto en un posible Cabildo Abierto de la ciudad en donde residía, a la vez que tenían acceso a la educación y al ejercicio de profesiones vinculadas a la administración estatal o al comercio ${ }^{10}$.

\section{La formación educativa inicial de Agrelo en Buenos Aires}

En continuidad con lo realizado por las mayorías de las familias criollas consideradas como "gente decente", Agrelo fue inscripto en la única institución educativa de su ciudad natal. Por entonces, las asimetrías de formación cultural de cada región permanecían marcadas. Mientras Buenos Aires conservaba únicamente el Colegio San Carlos, destinado a la formación inicial de la élite local, las Universidades cercanas que podían dar estatus de letrado, ya fuera eclesiástico o laico, eran Córdoba y Chuquisaca. Entre ambas, la afinidad principal de la elite de Buenos Aires era Chuquisaca por su apertura intelectual y por las vinculaciones existentes entre ambas ciudades gracias a su primacía como eje mercantil, mientras que Córdoba permanecía relegada a otros circuitos socio-económicos ${ }^{11}$. Así, parte de esta relación se debía a la dinámica comercial existente entre Potosí y Buenos Aires, que trascendía la circulación de plata. Existía un circuito mercantil interno sostenido entre ambos ejes que alimentaba a ciudades de paso en aquella articulación, lo que contribuía al fortalecimiento de la mercantilización del "espacio

\footnotetext{
9 JUMAR, Fernando [et al.]. El comercio ultramarino y la economía local en el complejo portuario rioplatense. Siglo XVIII. Anuario del IEHS. 2006, n. XXI, p. 236.

${ }^{10}$ El concepto de época de "gente decente" refería a aquellos que con mayores o menores ingresos tenían la posibilidad de acceder a espacios y funciones vinculadas al Estado, en oposición al "plebeyo" o los sectores bajos que no lograban incorporarse a dicho sector salvo que pudieran crear vínculos sanguíneos que le permitieran una adaptación cultural. Para estas categorías ver: DI MEGLIO, Gabriel, ¡Viva el bajo pueblo! La plebe urbana de Buenos Aires y la política entre la Revolución de Mayo y el rosismo. Buenos Aires: Prometeo, 2007, p. 53.

11 Conf. ASSADOURIAN, Carlos Sempat y PALOMEQUE, Silvia. Las relaciones mercantiles de Córdoba (1800-1830). Desarticulación y desmonetización del mercado interno colonial en el nacimiento del espacio económico nacional. En: IRIGOIN, María Alejandra y SCHMIT, Roberto (eds.). La desintegración de la economía colonial. Comercio y moneda en el interior del espacio colonial (1800-1860). Buenos Aires: Biblos, 2003, pp. 151-225.
} 
altoperuano"12.

En ese marco, Agrelo ingresó al Real Colegio de San Carlos, donde recibió la fuerte influencia de la perspectiva educativa que ostentaba la Institución. La misma poseía el aval de la monarquía y por entonces se encontraba bajo la dirección de José Luis Chorroarín. La entidad representó durante siete años su principal espacio de sociabilización, mediante la creación de vínculos con compañeros y profesores, muchos de los cuales serían sostenidos en el tiempo. Además, adquirió allí las primeras herramientas intelectuales para su formación, constituyendo así el sustrato o acervo sobre el que se desarrollaría la continuidad de su preparación erudita.

El Colegio constituía un espacio que nucleaba a las élites políticas y culturales, lo que facilitaba el ascenso de los alumnos mediante la creación de vínculos societarios, además de la formación personal. Fue creado como base de una futura universidad en la ciudad, por lo que buscaba sostener un alto nivel de exigencia. Su objetivo era formar letrados y hombres que sirvieran a la vigente autoridad política, la cual tendía a unificar los planes de estudios y darles un marcado carácter regalista a las teorías ético-políticas ${ }^{13}$. La Universidad era pensada como consecuencia del desarrollo político y portuario de la región, debido al crecimiento de su administración y necesidades operativas de índole político y jurídico. Sin embargo, las perspectivas de desarrollo no lograban cimentarse en la creación de aquella institución. El proyecto inicial del virrey Vertiz quedó postergado, sería recién retomado en 1817 por el Directorio Supremo de Pueyrredón, pero no habría de poder concretarse hasta 1821, bajo la administración provincial de Martín Rodríguez. Por todo ello, el Colegio era por entonces el único espacio formativo para los hijos de la elite en Buenos Aires.

La educación del Colegio recibida por Agrelo estaba en función de las necesidades de la monarquía y de la región portuaria rioplatense. Las mismas se nucleaban en la formación de letrados -expertos en derecho y sus fundamentos filosóficos- para la renovación y sostenimientos de las estructuras de la administración centralizadora borbónica. A pesar del enfoque que adquiría la Institución y que transmitía a sus alumnos, el Colegio no estaba facultado para emitir títulos, por lo que su función era destinada a preparar a los alumnos para los estudios universitarios $^{14}$. Ello implicaba necesariamente que el joven buscara con posterioridad una Universidad exterior a la región donde poder formarse, estas

\footnotetext{
${ }^{12}$ Sus fundamentos provenían del tráfico de esclavos y el contrabando previo a 1778. Sin embargo, las redes sociales y mercantiles establecidas continuaron bajo la nueva dinámica instaurada con la apertura del puerto de Buenos Aires. Ver: MOUTOUKIAS, Zacarías. Contrabando y control colonial. Buenos Aires, el Atlántico y el espacio peruano en el siglo XVII. Buenos Aires: Centro Editor de América Latina, 1988, pp. 46 y ss.

${ }^{13}$ LÉRTORA MENDOZA, Celina Ana. La enseñanza de la filosofía en tiempos de la colonia. Buenos Aires: Fundación para la educación, la cultura y la ciencia, 1979, p. 21.

${ }_{14}$ SALVADORES, Antonio. Real Colegio de San Carlos. En: Academia Nacional de la Historia. Historia de la Nación Argentina. Buenos Aires: El Ateneo, 1940, pp. 138 y 142. Sobre su desarrollo posterior consultar: GONZÁLEZ LEBRERO, Rodolfo. Promoting enlightment and virtues: The Colegio de la Unión del Sud, 1818-1823. En: GARAVAGLIA, Juan Carlos y PRO RUIZ, Juan (eds.). Latin American Bureaucreacy and the State Building Process (1780-1860). Cambridge Scholars Publishing Newcatle, 2013, pp. 302-346.
} 
podían ser Chuquisaca, Córdoba, Santiago de Chile o en casos muy particulares como Manuel Belgrano- una de la península. Por ello, se crearon vínculos con la Universidad de Chuquisaca para el reconocimiento de los certificados expedidos por el colegio ${ }^{15}$.

Mientras finalizaba sus estudios, realizó durante su último año en el Colegio donativos a la Corona, como símbolo de lealtad y sujeción ante su intención de continuar sus estudios para incorporarse al cuerpo administrativo de la monarquía. Fue realizado junto a su colega de curso, Julián Segundo de Agüero y no hay registros de otros compañeros que lo hubieran hecho ${ }^{16}$. Esto representaba una diferencia económica sustanciosa con respecto a la mayoría de los egresados que aspiraban a continuar sus estudios y que carecían de recursos para hacerlo. Lo que marcaba las mejoras en la condición financiera de su núcleo familiar.

La ponderación adquirida por Agrelo por parte de sus docentes le permitió contar con su respaldo para dirigirse a la Universidad Mayor Real y Pontificia de San Francisco Javier de Chuquisaca, con el objetivo de doctorarse en derecho e iniciar la carrera eclesiástica. Ello señalaba nuevamente la vinculación entre los claustros docente de Buenos Aires con los de Chuquisaca. En 1794 dejó el Colegio y partió hacia el norte del Virreinato para ingresar a la Universidad con el aval de las autoridades de San Carlos y parte de los ahorros conseguidos por su familia en el último tiempo.

\section{El eje de Chuquisaca: su desarrollo regional y educativo para las elites letradas}

Por entonces, Chuquisaca representaba el eje político y cultural del Alto Perú, su universidad poseía notable prestigio y era un referente para la continuidad de los estudios por parte de muchos hombres de Buenos Aires. La reorientación atlántica del Alto Perú, luego de su incorporación al Virreinato del Río de la Plata en 1776, se evidenció en el incremento de los contingentes de estudiantes rioplatenses, ya fuera desde Salta o desde Buenos Aires. La diversidad de los alumnos residentes, hizo de Charcas una ciudad activa y cosmopolita, que favorecía el intercambio cultural y permitía, rearticular lazos sociales con la elite altoperuana ${ }^{17}$.

La entidad contaba con el aval papal (expresado en el título de Pontificia) lo que le daba jerarquía en todo el orbe cristiano, mientras que el título de Real indicaba la autorización recibida por el monarca, lo que la convertía en una de las de mayor prestigio de la corona española y la única -junto a la de México- que portaba esta

\footnotetext{
${ }^{15}$ SALVADORES, Antonio. Real Colegio de San Carlos. Op. cit., p. 141. Si bien la mayoría de la elite de Buenos Aires se dirigía a Chuquisaca, algunos lo hacían también a Córdoba y otros menos a Chile, como los casos de Manuel Vicente Maza y Felipe Arana. Sobre esta cuestión, consultar: SERRANO, Sol. Universidad y nación. Chile siglo XIX. Santiago de Chile: Editorial Universitaria, 1993. ${ }^{16}$ Los donativos de P. J. Agrelo a "Su Majestad" fueron realizados el 20 de febrero y el 12 de julio de 1793. Esos mismos días se produjeron las dos donaciones de Agüero, registradas de igual manera. AGN, sala IX, legajo 8-7-12, fs. 166 y $10 \mathrm{v}$.

${ }^{17}$ Conf. THIBAUD, Clément. La Academia Carolina y la independencia de América. Los abogados de Chuquisaca (1776 - 1809). Sucre: Editorial Charcas; Fundación Cultural del Banco Central de Bolivia; Archivo y Biblioteca Nacionales de Bolivia, 2010.
} 
distinción en América. Los recursos fiscales con que contaba y la circulación mercantil que se producía en sus alrededores, facilitaba que Chuquisaca marcara el ritmo cultural de la región altoperuana y del Río de la Plata.

La carrera de derecho a la que ingresó Agrelo integraba tanto el romano (o civil) como el canónico. En sus cátedras, Agrelo profundizó los conocimientos de filosofía, derecho, matemática y teología. Bajo estos parámetros, Agrelo se formó como letrado durante los diez años que estudió en la Institución y en los que mantenía su residencia en la ciudad de Charcas. Compartió aulas con Mariano Moreno y Antonio Sanz, junto a quienes se recibió de Bachiller en Derecho en $1801^{18}$. Con uno o dos años de diferencia coincidió en los espacios universitarios con otros alumnos de trayectoria compartida como Pedro Miguel Aráoz, Pedro Medrano, Manuel Felipe Molina, José Ignacio Gorriti, Teodoro Sánchez de Bustamante, Manuel Antonio Castro y Andrés Pacheco y Melo entre otros ${ }^{19}$. Esta cuestión demuestra los vínculos adquiridos por Agrelo, contactos más o menos personales con futuros letrados de actuación contemporánea a él y con quienes compartiría instituciones 0 se enfrentaría políticamente. A la vez, evidencia la importancia cultural que dicha Universidad tenía para los futuros letrados nacidos en Buenos Aires.

Recibido de bachiller, continuó su formación para alcanzar el grado de doctor. Luego de aprobar un exigente ingreso, fue asiduo asistente a la Real Academia Carolina de Prácticas Juristas, donde desarrolló cursos teórico-prácticos. Allí, la Universidad y la política confluían en un ámbito de encuentro, socialización y debate entre las élites políticas y los hombres de saber. La Academia convocaba y enfrentaba tanto a graduados como a estudiantes y a funcionarios de la Audiencia, para reflexionar y discutir sobre cuestiones vinculadas tanto con las doctrinas jurídicas, como con los asuntos públicos ${ }^{20}$. Debido a ello era un espacio privilegiado para el ingreso a la vida político-administrativo del régimen borbónico por parte de los futuros egresados. En 1804 tras dar su audiencia pública, consistente en la disertación final de sus estudios, Agrelo recibió los títulos de doctor en teología y en derecho.

En su estadía como estudiante adquirió importantes contactos y vínculos que le abrirían nuevos horizontes. Como ensayo de una posible carrera clerical, predicó un sermón que fue ponderado por el ex oidor y entonces agente fiscal de la Real

\footnotetext{
${ }^{18}$ Agrelo obtuvo este título el 2 de junio con registro 285, mientras que Moreno lo haría el 1o de septiembre y Sanz el 2 de enero de 1802. Registro de egresados en cánones reproducidos en: ABECIA, Valentín. Historia de Chuquisaca. Sucre: Editorial Charcas, 1939, p. 356.

${ }^{19}$ Ibídem, pp. 350-358.

20 DE GORI, Esteban. La universidad de Charcas. Teoría y acción política. Revista Historia de la Educación Latinoamericana. 2010, vol. 14, pp. 174. Este tipo de debates e intervenciones políticas, era producido por letrados que criticaban la estructura burocrática desde el mismo gobierno al que pertenecían, pero lo realizaban con una estructura discursiva donde la búsqueda de reforma era siempre en beneficio del buen gobierno del rey. En esta línea se destacó Victorian de Villava, como fiscal de la Audiencia de Charcas y director de la Academia Carolina, quien impartió una fuerte influencia de la crítica reformista ilustrada en la institución, hasta su muerte en 1802. Han sido notorios los trabajos que ahondaron en sus influencias, entre los que se destacan: LEVENE, Ricardo. Vida y escritos de Victorián de Villava. Publicación del Instituto de investigaciones históricas. 1946, n. 95; y PORTILLO VALDÉS, José María (comp.). La vida atlántica de Victorián de Villava. Madrid: Fundación Mapfre, 2009.
} 
Audiencia, José Calvimontes, quién le ofreció y garantizó respaldo económico y social. Asociado personalmente al fiscal, Agrelo adquirió prestigio como su asesor y ayudante, a la vez que completaba sus prácticas profesionales. La estrecha relación construida entre ambos, respondía a la lógica de "patronazgo", mediante la cual un hombre de mayor jerarquía asociaba a su cargo y figura a otra persona de menor condición social, garantizándole así su inmersión dentro de estructuras sociales y estatales que de otra manera le serían negadas o de difícil acceso.

Ello fue determinante para que desistiera de iniciar la carrera eclesiástica y se mantuviera como abogado integrante de la fiscalía de la Audiencia ${ }^{21}$. Aquel vínculo fue finalmente sellado con el matrimonio entre Agrelo y la hija de Calvimontes, Isabel. De esa manera, lograba formar parte una familia de la élite local y posicionarse dentro de las redes sociales que articulaban a sus miembros dentro de un sistema de "sociedad cerrada" compuesta por "tramas de relaciones" que caracterizaba a las élites virreinales ${ }^{22}$. Agrelo adquiría así una legitimidad social, pudiendo entonces contar con aliados o personas vinculadas a dicha familia que ocupaban otros cargos estratégicos en la región. Sus lazos de socialización producían finalmente sus efectos políticos al posicionarlo dentro de la estructura de gobierno.

Gracias a ella ascendió rápidamente en la región. Logró ser asesor letrado del Subdelegado de Chinchas, Benito José Goyena ${ }^{23}$, cuya autoridades extendía dentro de la división de la Intendencia de Potosí. Era una región de gran circulación mercantil y de plata, a la vez que se encontraba en una zona con importante cantidad de población indígena que actuaba como sustento productivo. Con la muerte de Goyena, Agrelo logró adquirir el cargo de Subdelegado provisorio. Su perfil de hombre formado como doctor en derecho, sus años como asesor y sus contactos familiares le permitían aspirar a ser el sucesor del subdelegado fallecido ${ }^{24}$.

De esa manera, Agrelo lograba hacer carrera político-jurídica dentro del orden borbónico gracias a su establecimiento en un eje productivo y fiscal importante. Dicho espacio era articulador de la circulación mercantil regional y por sus recursos podía garantizar el mantenimiento de una mayor cantidad de funcionarios, vinculados a una élite más fortalecida que la de Buenos Aires. Así, el espacio altoperuano le dio a Agrelo la posibilidad de un ascenso social y político rápido, que difícilmente hubiera conseguido en su ciudad natal.

\footnotetext{
${ }^{21}$ Así lo aseveraba su hijo, Martín Agrelo en la biografía escrita de su padre. Conf. AGRELO, Martín. Rasgos biográficos del Señor Doctor D. Pedro José Agrelo, Buenos Aires, Imprenta del Porvenir, 1864.

${ }^{22}$ Este concepto fue desarrollado por Bernard Lavallé, en referencia a las redes constituidas por los miembros de grupos familiares de las élites locales que permitían construir vínculos y asociaciones de poder mediante alianzas familiares entre quienes ocupaban cargos estratégicos. Consultar: LAVALLÉ, Bernard. El mercader y el marqués. Las luchas de poder en el Cuzco (1700-173). Lima: Banco Central de Reserva del Perú, 1988.

${ }^{23}$ Sobre la reconocida trayectoria Goyena a cargo del gobierno de subdelegaciones ver: ACEVEDO, Edberto O. Las intendencias altoperaunas en el Virreinato del Río de la Plata. Buenos Aires: Academia Nacional de la Historia, 1992, p. 158.

${ }^{24}$ CORREA LUNA, Carlos. La iniciación revolucionaria. Op. cit., p. 8.
} 


\section{Buenos Aires: cambio de eje productivo-fiscal y reorganización estructural de sus letrados}

Ante la crisis de legitimidad del poder central español y con el estallido de la Revolución de Mayo en 1810, colapsaron las estructuras jurídico-políticas tradicionales de la monarquía borbónica. Esa situación de inestabilidad afectó los fundamentos fiscales-productivos, la articulación de los ejes portuarios y así también el desarrollo de la carrera de la mayoría de los letrados de la región. Agrelo no fue su excepción, luego de una situación de ambivalencia política donde el subdelegado interino pretendió conservar su autoridad local, debió renunciar ante las acusaciones de ser realista y regresó a Buenos Aires junto con toda su familia. El tránsito no fue solo de un espacio regional a otro, sino que representó también una redefinición política, donde Agrelo abandonó su cercanía a los grupos realistas altoperuanos y buscó integrarse en la dirigencia revolucionaria.

Apenas establecido en la ciudad, buscó reafirmar la trama relacional y política que mantenía en la capital virreinal con los principales dirigentes de la Revolución. Se reunió inmediatamente con Mariano Moreno, apelando a su amistad de juventud sellada con su nombramiento como testigo de su casamiento con María Guadalupe Cuenca $^{25}$. Gracias a ello se vinculó a los espacios de socialización de los grupos revolucionarios más radicales, a fin de mostrar su filiación política. Colaboró con el grupo morenista, integró la Sociedad Patriótica y fue redactor de la Gazeta de Buenos Ayres durante $1811^{26}$. Todo ello le permitió reubicarse en la elite política de la ciudad capital. Desde allí, logró alcanzar cargos importantes como: fiscal de la Cámara de Apelaciones y diputado de la Asamblea del Año XIII. Desde allí propuso medidas económicas destinadas a afrontar los costos de la guerra. Abogó por el establecimiento de empréstitos forzosos, los cuales también se encargó de recaudar, a la vez que dio moción para la aprobación de acuñación de la primera moneda nacional. Al respecto, aseguró en El Redactor, que era necesario garantizar su circulación al mismo valor que en el sistema borbónico a fin de no generar mayores alteraciones fiscales ${ }^{27}$.

Sin embargo, su defensa de la primacía de Buenos Aires y la eliminación de que la provincia que representaba, Salta, fuera quien cobrara los empréstitos forzosos le causó la disputa con su colega diputado por aquella ciudad, Moldes. La pelea que llegó a expresarse en violencia física durante las sesiones representó la tensión existente entre la lógica fiscal de Buenos Aires y la del norte, que se hallaba debilito por la guerra y la pérdida del circuito mercantil con el Alto Perú28.

Por entonces se veían nuevamente afectados los ejes portuarios y sus implicancias regionales. Con la guerra revolucionaria, el Alto Perú -y Potosí en

\footnotetext{
${ }^{25}$ GOLDMAN, Noemí. Mariano Moreno. De reformista a insurgente. Buenos Aires: Edhasa, 2016, p. 53.

${ }^{26}$ Ello se encuentra trabajo en: EIRIS, Ariel Alberto, La concepción continental de la guerra revolucionaria en el discurso periodístico de Pedro José Agrelo desde la Gazeta de Buenos Ayres en 1811. Épocas. 2014, n. 9.

${ }^{27}$ El Redactor de la Asamblea, 31 de julio de 1813.

${ }^{28}$ TERNAVASIO, Marcela. Gobernar la revolución. Op. cit., p. 142.
} 
particular- quedó fuera de la órbita revolucionaria salvo pocas excepciones de las incursiones militares de Belgrano y José Rondeau en 1813 y 1815 respectivamente. Como consecuencia, se perdieron sus ingresos fiscales y dejó de representar un eje cultural y formativo. Así, la nueva gravitación productiva pasó con especial preponderancia al Litoral, en particular a Buenos Aires, cuya aduana permanecía como centro de la recaudación y financiamiento de los sucesivos gobiernos revolucionarios ${ }^{29}$.

Este cambio fortaleció las cuestiones identitarias regionales, agravando la tensión existente entre el interior y la región portuaria de Buenos Aires. Ello se evidencia en los primeros reclamos federales del Litoral, centrados en la lógica de un poder representativo y una financiación no equitativa en función de los ingresos fiscales locales ${ }^{30}$. No obstante, Buenos Aires se sumó a aquellos planteos, al exigir un "sistema federal" que garantizara el mayor ingreso de su propia aduana para su ciudad y hinterland, y no para financiar al interior del territorio y la guerra que se libraba lejos de aquella ciudad ${ }^{31}$.

Agrelo no permaneció relegado a esta situación. Integró desde 1816 el primer grupo federal de Buenos Aires, colaborando en sus críticas hacia la administración del Director Pueyrredón por las presiones fiscales sobre Buenos Aires y su relegamiento ante las campañas sanmartinianas y del Alto Perú. Desde la prensa buscó seguir estando vinculado a la dirigencia política local, proponiendo modelos jurídicos para la organización nacional a través del periódico El Independiente (18161817). El carácter republicano de las ideas jurídicas allí esbozadas, lo llevó a una progresiva tensión con el Directorio, lo que le significó su exilio a Estados Unidos en 1817. Fue el único de los desterrados que regresó a los pocos meses, sin tener el perdón del gobierno. Luego de varios meses de arresto por su regreso no autorizado, Agrelo logró la amnistía de Pueyrredón. Entonces, inició una nueva publicación, El Abogado Nacional (1818-1819), la cual era de carácter más moderado y buscaba tener la aprobación del Directorio ${ }^{32}$. Así, se evidencia como pese a las dificultades políticas. Agrelo buscó permanecer en Buenos Aires e integrarse a su dirigencia, pese al destierro sufrido en 1817.

El mismo acabó por manifestarse tras los sucesos de la Batalla de Cepeda y la caída del poder central de las Provincias Unidas. En aquel convulsionado año de 1820, el letrado actuó en sucesivos gobiernos. Fue asesor letrado de los

\footnotetext{
${ }^{29}$ CORTÉS CONDE, Roberto. La economía argentina... Op. cit., pp. 85-86. Para ampliar la cuestión, consultar: HALPERÍN DONGHI, Tulio. Guerra y finanzas en los orígenes del Estado argentino (17911850). Buenos Aires: Editorial de Belgrano, 1982.

${ }^{30}$ Conf. ZORRAQUín BECÚ, Ricardo. El federalismo argentino. Buenos Aires: Perrot, 1958.

${ }^{31}$ Por entonces, existía una confusión entre los conceptos de "federalismo" y "confederación". Ambos hacían referencias a gobiernos descentralizados, aunque no existía una precisión conceptual sobre la diferencia de ambos términos. Fabián Herrero entiende que el reclamo de Buenos Aires de 1816 es de carácter "confederacional". HERRERO, Fabián. La revolución dentro de la revolución. En: HERRERO, Fabián (comp.). Revolución. Política e ideas en el Río de la Plata durante la década de 1810. Rosario: Prohistoria, 2010, pp. 100-101.

${ }^{32}$ Sobre el contenido de sus escritos periodísticos, el exilio y la búsqueda de Agrelo por regresar a Buenos Aires con inmediatez a su arribo en Estados Unidos, consultar: EIRIS, Ariel Alberto. Cambios en la utilización de redes políticas durante el exilio de Pedro José Agrelo a Estados Unidos en 1817 y su retorno en 1818. PolHis. Ene./Jun. 2019, año 12, n. 23.
} 
gobernadores federales Manuel de Sarratea y Miguel Estanislao Soler, a la vez que promovió el "motín del Cabildo" contra el gobernador directorial Martín Rodríguez $z^{33}$. Buscó así instaurar un poder de línea federal local, capaz de fortalecer la autoridad regional, pero tras su fracaso el letrado debió partir al exilio junto con políticos allegados $^{34}$. Pronto, con el fortalecimiento de la autoridad de Rodríguez, la provincia buscaría reconstituirse jurídicamente y organizarse de forma autónoma a la influencia del litoral.

\section{El rol de Agrelo en Entre Ríos y el intento de un nuevo eje portuario-cultural}

Con la caída del poder central rioplatense y la consecuente atomización de las Provincias Unidas, se fortalecieron las peleas entre ellas por la hegemonía política y económica regional. Entre Ríos, bajo la órbita de Artígas, había logrado constituirse como una provincia rica y pujante por el comercio regional. Su población se había duplicado en la década de 1810, a la vez que se expandía la fundación de pueblos y crecimiento comercial ${ }^{35}$. Su desarrollo regional estaba en diálogo con sus aspiraciones políticas, materializadas en la proclamación de la República Entrerriana en 1820 bajo el liderazgo del gobernador Francisco Ramírez. Sin embargo, esa búsqueda de hegemonía fue franqueada cuando cayó su alianza con Santa Fe, al poco tiempo de la batalla de Cepeda. Ello traería el desenlace de la invasión a Santa Fe y Córdoba, que finalizó con la ejecución de Ramírez por parte de las fuerzas del santafesino Estanislao López.

En ese contexto, un grupo de militares porteños al mando de Lucio N. Mansilla se había sumado a las fuerzas de Ramírez con el consentimiento del entonces gobernador Sarratea. Sin embargo, el grupo había tomado distancia de Ramírez, cuando éste quiso romper su alianza con Santa Fe y Córdoba. Con la muerte de Ramírez, su pariente y allegado, Ricardo López Jordán (padre), se proclamó gobernador, pero fue depuesto por una sublevación encabezada por Mansilla y sus fuerzas. Así Mansilla siendo porteño, se proclamó gobernador de Entre Ríos el 21 de septiembre de 1821 y tuvo el apoyo de un grupo de allegados entrerrianos y porteños con los cuales buscó reorganizar institucionalmente la provincia.

En ese contexto, apenas fracasado el motín del Cabildo, Agrelo viajó con su familia al Litoral en octubre de 1820. Mediante la recomendación de Francisco Martínez, consiguió el respaldo de Mansilla, a quien acompañó en los momentos en los que éste se convertiría en el nuevo gobernador de Entre Ríos ${ }^{36}$. Bajo su administración se constituyó un grupo de letrados, de ideología federal, que entendía

\footnotetext{
${ }^{33}$ HERRERO, Fabián. Un golpe de Estado en Buenos Aires durante octubre de 1820. Anuario IEHS. 2003, n. 18, p. 71.

${ }^{34}$ BERUTI, Juan Manuel. Memorias curiosas. Tomo IV. Buenos Aires: Honorable Senado de la Nación, 1960, p. 3935.

${ }^{35} \mathrm{Al}$ respecto del desarrollo económico en la región consultar: SCHMIT, Roberto y DJENDEREDJIAN, Julio. Los límites de la gran empresa agraria en el nacimiento del capitalismo rioplatense. Una estancia entrerriana durante la primera mitad del siglo XIX. Anuario IEHS. 2011, vol. 25, pp. 395-414 y URQUIZA ALMANDOZ, Óscar. Historia económica y social de Entre Ríos (16001854). Paraná: Banco Unido del Litoral, 1978, pp. 41 y 43.

${ }^{36}$ Carta de Francisco Martínez a Lucio N. Mansilla, 12 de diciembre de 1820. Archivo General de la Provincia de Entre Ríos, Sección Gobierno, legajo 8.
} 
que se requería de una reorganización jurídica estable para fortalecer el poder político local e incrementar el desarrollo económico de la región. Agrelo pasó a desempeñarse como asesor del gobierno e integró ese grupo letrado que tomó la resolución de establecer un nuevo orden institucional.

Con ese objetivo, fue convocada una Convención Constituyente Provincial, de la cual Agrelo fue secretario y asesor de los redactores de la Constitución provincial en 1822. Si bien se le ha adjudicado la redacción del proyecto original, la documentación señala a otro letrado, Casiano Calderón, como su principal redactor $^{37}$. Es de suponer que el proyecto originario fuera de él, aunque el desempeño clave de Agrelo en la secretaría de la Convención le permitió tener una relevancia central en las disposiciones constitucionales adoptadas. Debido a la confianza adquirida por Mansilla, el letrado permaneció como ministro de guerra y mantuvo centralidad en su gobierno ${ }^{38}$. De esa manera, sus conocimientos jurídicos permitían contribuir al desarrollo de un espacio que buscaba ser un nuevo eje productivo.

Sin embargo, el mismo quedaría relegado ante la primacía de Buenos Aires, que lograría imponer su hegemonía a la de Santa Fe. Los cambios políticos eran favorecidos por la ubicación geográfica del puerto de Buenos Aires, que continuaba siendo estratégico para el comercio atlántico, es desmedro del Litoral. Ese desequilibrio acabaría por frenar la expansión de las ciudades-puerto del Interior. Buenos Aires, pasó a ser el eje de la dinámica del desarrollo regional y un mediador obligado en las posibilidades de inserción de las provincias en el circuito económico. De esta manera se erigió como centro hegemónico del nuevo espacio ${ }^{39}$.

Por su parte, la primacía política federal que había ganado Agrelo, lo llevó a ser blanco de agresiones políticas. Especialmente, sufrió el ataque callejero de una persona que, aparentemente en estado ebrio, le cortó con una espada sus manos, causándole la inmovilidad de varios dedos ${ }^{40}$. A su vez, su desgaste entre las autoridades provinciales y el fortalecimiento del eje portuario de Buenos Aires, impulsaron a que el letrado decidiera alejarse de aquella provincia para regresar a su ciudad natal. En ese contexto, se produjo un cambio político significativo, con a la sanción del decreto de amnistía firmado por el gobernador Rodríguez hacia determinadas figuras que habían sido centrales en la crisis de 1820. Esas personas eran esencialmente Sarratea, Alvear y Agrelo.

Esto se daba ante un nuevo escenario político, donde luego del Tratado del Cuadrilátero el 25 de enero de 1822, las provincias de Buenos Aires, Entre Ríos, Santa Fe y Corrientes habían establecido la paz entre ellas y se comprometían a no enviar representantes a la convocatoria de Congreso Constituyente que realizaba Juan Bautista Bustos en Córdoba. Si bien Entre Ríos no mantuvo una clara alianza

\footnotetext{
${ }^{37} \mathrm{BOSCH}$, Beatriz. El estatuto provisorio constitucional de Entre Ríos. Boletín del Instituto de Investigaciones Históricas. 1942-1943, año XXI, tomo XXVII, n. 93-96, p. 228.

${ }^{38}$ GIANELLO, Leoncio. Historia de Entre Ríos, 1520-1910. Paraná: Ministerio de Educación, 1951, pp. 272-273.

${ }^{39}$ FERRER, Aldo, La economía argentina. Desde sus orígenes hasta principios del siglo XXI. Buenos Aires: Fondo de Cultura Económica, 2004, pp. 67 y 81.

${ }^{40}$ AGRELO, Martín. Rasgos biográficos... Op. cit., p. 13.
} 
con Corrientes luego de este acuerdo, si lo hizo con Buenos Aires, cuyas relaciones mejoraron posiblemente ayudadas por el diálogo entre autoridades de cuño porteño.

Ante este giro, Agrelo como ministro de Mansilla envío el 2 de junio de 1822 una carta al secretario de gobierno de Rodríguez, Bernardino Rivadavia, donde le pedía disculpas por los enfrentamientos políticos ocurrido con anterioridad (en lo personal habían tenido una rivalidad singular en torno a los sucesos de 1812 y la caída del Primer Triunvirato) $)^{41}$. Rivadavia respondió favorablemente, mientras por orden del gobernador, felicitaba al letrado y al gobierno entrerriano por el orden institucional alcanzado en Entre Ríos ${ }^{42}$.

A partir de estos lazos políticos creados, Agrelo tuvo la oportunidad de viajar como enviado oficial de Entre Ríos, a la provincia de Buenos Aires. Allí, se entrevistó en persona con Rodríguez y Rivadavia, a quienes les garantizó el acercamiento dispuesto por la provincia que representaba. Esta visita fue especialmente agradecida a Mansilla, por parte de ambos funcionarios bonaerense que reconocieron la importancia de concretar una alianza entre ambas provincias gracias a las gestiones de Agrelo ${ }^{43}$.

Aquella visita, pudo haberle servido al letrado para alejarse de las tensiones entrerrianas que le habían causado aquel atentado. Es posible que haya encontrado en su ciudad natal, la estabilidad que deseaba, lo que se refleja en la permanencia en aquella ciudad y la adquisición de un pasaporte, mientras seguía actuando como "enviado" del gobernador Mansilla". Agrelo permaneció como nexo entre ambas provincias, consiguiendo incluso una protección especial para los hijos del gobernador entrerriano que podían establecerse en Buenos Aires ${ }^{45}$.

Esas conexiones y relaciones políticas asentadas, habrían permitido que Agrelo decidiera alejarse definitivamente de Entre Ríos, y establecerse en su ciudad natal. Posiblemente, especulando o con la certeza de que tendría un cargo o función dada por el gobierno de Buenos Aires a principios de 1823.

\section{Agrelo ante la creación de la Universidad de Buenos Aires y el fortalecimiento de Buenos Aires como eje portuario-cultural}

Establecido de regreso a Buenos Aires, Agrelo fue parte de la reestructuración institucional, cultural y formativa que sufría la ciudad. La paz y el orden logrado por el gobierno de Rodríguez, permitió que la ciudad-puerto vuelva a contar con recursos suficientes para constituir el espacio formativo y cultural que permanecía relegado desde los tiempos borbónicos. La proyectada universidad de la ciudad,

\footnotetext{
${ }^{41}$ Carta de Pedro José Agrelo a Bernardino Rivadavia, 2 de junio de 1822. Archivo del Museo Mitre, A1.EO. № 1346.

${ }^{42}$ Carta de Bernardino Rivadavia a Pedro José Agrelo, 18 de junio de 1822, en: Universidad de Buenos Aires-Facultad de Filosofía y Letras, Documentos para la historia argentina, tomo 13, Bueno Aires, Compañía Sud-Americana de Billetes de Banco, 1911, p. 162.

${ }^{43}$ Carta Martín Rodríguez y Bernardino Rivadavia a Lucio N. Mansilla, 8 de agosto de 1822, en: Ibídem, p. 165.

${ }^{44}$ Carta de Bernardino Rivadavia a Pedro José Agrelo, 19 de septiembre de 1822, en: Ibídem, p. 175.

${ }^{45}$ Carta de Bernardino Rivadavia a Lucio N. Mansilla, 19 de febrero de 1822, en: Ibídem, pp. 202-203.
} 
postergada desde virrey Vertiz, pudo constituirse recién entre 1821 y 1822 gracias a la nueva administración provincial, que procuró destinar esfuerzos económicos y administrativos para disponer de un espacio formativo propio para su elite, en momento donde había desaparecido la unidad de las Provincias Unidas ${ }^{46}$.

De esa manera Buenos Aires lograba, gracias a su ubicación espacial y a su primacía como eje portuario, constituir un espacio formativo para su elite ${ }^{47}$. Se eliminaba así la problemática del estudio en otra región, lo que le daba autonomía cultural a la ciudad. La misma podía así instruir a sus letrados y demás agentes locales, administrativos y productivos.

El primer rector y principal organizador de la Universidad fue Antonio Sanz, compañero de Agrelo en Chuquisaca. En su diseño de estudios, se destinó un Departamento de Jurisprudencia donde colaboraban importantes figuras de la Academia de Jurisprudencia de Buenos Aires, la cual había sido constituida en 1818, siguiendo el modelo de la Carolina de Chuquisaca, por lo que buscaba actuar como base teórica y asesora para el gobierno, a la vez de lograr la formación de letrados destinados a su servicio ${ }^{48}$. Ese espacio socio-cultural fue fortalecido con la publicación del periódico Argos y la extensión cultural mediante la formación de una opinión pública particular ${ }^{49}$. La influencia de este grupo de letrados asociados, entre los que estaba Sanz, fue central para la conformación de la carrera de derecho en la Universidad.

En ese marco, se dispuso la creación de la cátedra de Economía Política destinada a los estudiantes de derecho. La misma implicaba el estudio de la administración de la hacienda y de las finanzas públicas, lo cual le fue encomendado a Vicente López y Planes, quien adjudicó problemas personales para asumir la responsabilidad ${ }^{50}$. Por ese motivo, el 28 de noviembre de 1823 se designó como profesor titular de la misma a Agrelo.

Es de señalar, que la resolución que nombraba a Agrelo como profesor titular era un decreto del gobierno firmado por Rodríguez y Rivadavia. Allí expresaban el deseo de "jerarquizar en el país los conocimientos y el estudio de la economía política" ante la "urgencia con que la situación de estos pueblos reclama la adquisición de tan

${ }^{46}$ Conf. HALPERÍN DONGHI, Tulio. Historia de la Universidad de Buenos Aires. Buenos Aires: Eudeba, 1962y BUCHBINDER, Pablo. Historia de las Universidades Argentinas. Buenos Aires: Sudamericana, 2005.

${ }^{47}$ La importancia de la Universidad para formar a los agentes portuarios locales, era consecuencia del crecimiento económico de la región, a la vez que la misma la fortalecía. A su vez, lograba cimentar la cuestión identitaria y cultural región. Como modelo analítico ver: DE MARCO, Miguel Ángel (h). Ciudad Puerto, Universidad y Desarrollo Regional. Rosario 1919-1968. Rosario: CEHDRE, 2013.

${ }^{48}$ LEVENE, Ricardo. La Academia de jurisprudencia de Buenos Aires y su labor en orden a los estudios de derecho patrio y la reforma de la legislación. Buenos Aires: Universidad de Buenos Aires, 1941 , p. 333

${ }^{49}$ GALLO, Klaus y BATTICUORE, Graciela. Ideas, literatura y opinión pública. En: TERNAVASIO, Marcela (dir.). Historia de la provincia de buenos Aires. Tomo 3: De la organización provincial a la federalización de Buenos Aires (1821-2880). Buenos Aires: Edhasa, 2013, p. 322.

${ }^{50}$ FASOLINO, Nicolás. Vida y obra del primer rector y cancelario de la Universidad de Buenos Aires, presbítero Antonio Sanz. Buenos Aires: Coni, 1921, p. 241. 
importantes nociones y aun, lo que importan más, el crearse la aplicación de la teoría de esta ciencia a la práctica correspondiente a países tan nuevos". Allí se expresaba el deseo por adquirir un nivel de conocimiento teórico similar al de los países considerados más desarrollados, por lo que establecían el texto que se debería utilizar como manual de la cátedra. El mismo era la obra del inglés James Mill, Elementos de Economía Política, publicada en Londres en $1821^{51}$.

La utilización de aquella obra, referente del utilitarismo inglés en auge, señalaba la preocupación de los letrados porteños por incorporarse al esquema de pensamiento internacional y británico en especial, entendiendo que éste podría abrir oportunidades de desarrollo regional, tanto económico como político ${ }^{52}$. Es importante entender la cátedra destinada al concomiendo de las políticas fiscales y financieras en momentos donde las "reformas" impulsadas por Rivadavia tendían a transformar la dinámica económica y productiva de la provincia, con lo que es de suponer que pretendiera que esta materia fuera el sustento intelectual para los futuros funcionarios que continuarían aquellas iniciativas.

El desarrollo de esta cátedra sólo pudo durar de forma completa la cursada correspondiente a 1824. Año de auge de la hegemonía de Buenos Aires, cuya estabilidad institucional y consolidación política se materializó en ser la sede del Congreso General Constituyente inaugurado en aquel año en la ciudad portuaria $^{53}$.La cátedra de Economía Política fue suprimida por la reforma del plan de estudio el 26 de abril de 1825. Pese a ello, Agrelo permaneció como docente en la cátedra de Derecho Natural y de Gentes hasta el 6 de diciembre de 1829, cuando frente a la asunción de Juan Manuel de Rosas como gobernador de Buenos Aires, el letrado sería elegido fiscal de Gobierno, cuya responsabilidad pública implicó su alejamiento del claustro universitario y el inicio de su última etapa como profesional letrado, pero en continuidad con la órbita de Buenos Aires.

\section{Conclusiones}

La necesidad de un letrado como Agrelo de desempeñar su función en vinculación con un gobierno, lo llevó a circular por diferentes espacios productivos y portuarios en función de la primacía económica que estos adquirían. Tal crecimiento mercantil les permitía a esas ciudades impulsar el desarrollo institucional y cultural, que generaba la demanda de letrados. No obstante, su ciudad natal fue siempre un

\footnotetext{
${ }^{51}$ Decreto del 28 de noviembre de 1823, reproducido en: Registro oficial de la provincia de Buenos Aires, Buenos Aires, José Luis y Rossi, 1825, p. 92. La obra fue traducida con velocidad dado el especial interés de Rivadavia, que le encargó tal tarea a Santiago Wilde. Ver: UNZUÉ, Martín. Historia del origen de la Universidad de Buenos Aires (A propósito de su 190 aniversario). Revista Iberoamericana de Educación Superior (RIES) [en línea]. 2012, vol. III, n. 8. Disponible en $<$ http://www.scielo.org.mx/scielo.php?script=sci arttext\&pid=S2007-28722012000300004>.

${ }^{52}$ Conf. DÁVILO, Beatriz. Los derechos, las pasiones, la utilidad: debate intelectual y lenguajes políticos en Buenos Aires (1810-1827). Caseros: Universidad Nacional de Tres de Febrero, 2011, pp. 216 y ss.

${ }^{53}$ Esta primacía había sido rivalizada desde 1820 con Santa Fe y Córdoba especialmente. La elección definitiva de Buenos Aires como sede del Congreso mediante el Tratado del Cuadrilátero, señala la hegemonía política, económica y cultural alcanzada. Ver: BARBA, Enrique, Unitarismo, federalismo, rosismo. Buenos Aires: Ediciones Pannedille, 1972, p. 49.
} 
espacio privilegiado al momento de tener que optar entre diferentes ejes en disputa.

Durante el Virreinato, se observa la primacía cultural de Chuquisaca, asociada a su trayectoria en el desarrollo económico regional, frente a un creciente Buenos Aires que aún no lograba constituir espacios formativos propios para la elite local. En el Alto Perú, Agrelo logró recibirse de letrado, integrarse a la elite local y ascender en la administración real. La primacía cultural de Chuquisaca cayó con la Revolución de Mayo y su consecuente guerra, lo que forzó a que Agrelo se trasladara con sus conocimientos y experiencia de gestión adquiridos en el Alto Perú hacia Buenos Aires.

El cambio de eje regional, significó también una redefinición política en su trayectoria. Definido como revolucionario, se integró a la dirigencia política. Desde allí, adquirió un perfil localista que le permitió integrar los primeros grupos federales de Buenos Aires. Su intención de permanecer en la ciudad fue permanente, pese al destierro sufrido en 1817 y a la Atomización de las Provincias ocurrido en 1820. Agrelo buscó integrar los gobiernos provinciales de tendencia federal que se sucedieron aquel año. Ante el fracaso de los mismos, debió exiliarse a Entre Ríos, donde tenía vínculos socio-políticos. No obstante, este nuevo espacio representaba una región de crecimiento económico y pujante en la hegemonía regional. Se integró a su dirigencia provincial, por lo que tomó parte de la organización institucional y actuó en su gobierno como Ministro.

Sin embargo, el nuevo espacio no era capaz de superar a la reorganizada Buenos Aires, la cual se fortalecía como eje político y económico regional. Agrelo estableció vínculo con su parte allí, Bernardino Rivadavia, y se asoció a la dirigencia política provincial que se encausaba detrás del reformismo de su ministro. Integrado a los grupos reformistas, Agrelo tomó participación de la elite cultural en un nuevo rol como docente. Sus materias permitían formar funcionarios y administradores de las finanzas bajo la lógica de las reformas rivadavianas que pretendían robustecer la ciudad-puerto de Buenos Aires.

De esa manera, se evidencia cómo la trayectoria de Agrelo estuvo en diálogo con los cambios de ejes productivos en la región. El letrado se desplazado entre tres espacios centrales: Alto Perú, Buenos Aires y Entre Ríos, en función de la primacía regional y la conveniencia política de poder integrar la dirigencia local. Agrelo es un caso que señala la circulación de agentes letrados, la cual implicó también la transferencia de elementos culturales en función de la primacía de los diferentes ejes productivos o portuarios que fueron articulándose en la transición del siglo XVIII al XIX, a lo largo del espacio portuario rioplatense.

\section{Bibliografía y fuentes}

ABECIA, Valentín. Historia de Chuquisaca. Sucre: Editorial Charcas, 1939, p. 356.

ACEVEDO, Edberto O. Las intendencias altoperaunas en el Virreinato del Río de la Plata. Buenos Aires: Academia Nacional de la Historia, 1992. 
AGN, sala IX, legajo 8-7-12, fs. 166 y $10 \mathrm{v}$.

AGRELO, Martín. Rasgos biográficos del Señor Doctor D. Pedro José Agrelo, Buenos Aires, Imprenta del Porvenir, 1864.

Archivo del Museo Mitre, A1.EO. № 1346.

Archivo General de la Provincia de Entre Ríos, Sección Gobierno, legajo 8.

ASSADOURIAN, Carlos Sempat y PALOMEQUE, Silvia. Las relaciones mercantiles de Córdoba (1800-1830). Desarticulación y desmonetización del mercado interno colonial en el nacimiento del espacio económico nacional. En: IRIGOIN, María Alejandra y SCHMIT, Roberto (eds.). La desintegración de la economía colonial. Comercio y moneda en el interior del espacio colonial (1800-1860). Buenos Aires: Biblos, 2003, pp. 151-225.

BARBA, Enrique, Unitarismo, federalismo, rosismo. Buenos Aires: Ediciones Pannedille, 1972.

BARRIERA, Darío. Del gobierno de los jueces a la desjudicialización del gobierno. Desenredos en la trenza de la cultura jurisdiccional en el Río de la Plata (Santa Fe, 1780-1860). En: AGÜERO, A.; SLEMIAN A. y FERNÁNDEZ DE SOTELO, Rafael Diego (coords.). Jurisdicciones, Soberanías, Administraciones: Configuración de los espacios políticos en la construcción de los estados nacionales en Iberoamérica. Córdoba: Editorial de la Universidad Nacional de Córdoba; México: El Colegio de México, 2018, pp. 371-406.

BERUTI, Juan Manuel. Memorias curiosas. Tomo IV. Buenos Aires: Honorable Senado de la Nación, 1960.

$\mathrm{BOSCH}$, Beatriz. El estatuto provisorio constitucional de Entre Ríos. Boletín del Instituto de Investigaciones Históricas. 1942-1943, año XXI, tomo XXVII, n. 9396.

BOTANA, Natalio. La Libertad Política y su Historia. Buenos Aires: Ed. Sudamericana, 1991.

BUCHBINDER, Pablo. Historia de las Universidades Argentinas. Buenos Aires: Sudamericana, 2005.

CHIARAMONTE, José Carlos. Nación y Estado en Iberoamérica: El lenguaje político en los tiempos de las independencias. Buenos Aires: Sudamericana, 2004.

CORREA LUNA, Carlos. La iniciación revolucionaria: El caso del doctor Agrelo, Buenos Aires, 1915.

CORTÉS CONDE, Roberto. La economía argentina en el largo plazo. Siglos XIX y XX. Buenos Aires: Sudamericana, 1997. 
DÁVILO, Beatriz. Los derechos, las pasiones, la utilidad: debate intelectual y lenguajes políticos en Buenos Aires (1810-1827). Caseros: Universidad Nacional de Tres de Febrero, 2011.

DE GORI, Esteban. La universidad de Charcas. Teoría y acción política. Revista Historia de la Educación Latinoamericana. 2010, vol. 14.

DE MARCO, Miguel Ángel (h). Ciudades portuarias, desarrollo regional y preservación del patrimonio portuario. Propuestas para la conformación de redes de estudios interdisciplinarios, internacionales y locales. Red Sociales, Revista del Departamento de Ciencias Sociales. 2017, vol. 4, n. 2, p. 38.

DE MARCO, Miguel Ángel (h). Ciudad Puerto, Universidad y Desarrollo Regional. Rosario 1919-1968. Rosario: CEHDRE, 2013.

DE MARCO, Miguel Ángel. Historia del periodismo argentino. Buenos Aires: Educa, 2006.

DE MARCO, Miguel Ángel (h). La Ciudad puerto como fundamento identitario de los actores del desarrollo institucional y económico regional frente las grandes crisis internacionales. El caso de Rosario (Argentina), 1890-2001. Nuevo Mundo. Mundos Nuevos [en línea]. 2016. [Consulta: 19-07-2017]. Disponible en $<$ https://journals.openedition.org/nuevomundo/70000>.

DI MEGLIO, Gabriel, ¡Viva el bajo pueblo! La plebe urbana de Buenos Aires y la política entre la Revolución de Mayo y el rosismo. Buenos Aires: Prometeo, 2007.

EIRIS, Ariel Alberto, La concepción continental de la guerra revolucionaria en el discurso periodístico de Pedro José Agrelo desde la Gazeta de Buenos Ayres en 1811. Épocas. 2014, n. 9.

EIRIS, Ariel Alberto. Cambios en la utilización de redes políticas durante el exilio de Pedro José Agrelo a Estados Unidos en 1817 y su retorno en 1818. PolHis. Ene./Jun. 2019, año 12, n. 23.

El Redactor de la Asamblea. Buenos Aires, 1813.

FASOLINO, Nicolás. Vida y obra del primer rector y cancelario de la Universidad de Buenos Aires, presbítero Antonio Sanz. Buenos Aires: Coni, 1921.

FEDELE, Javier y DOMÍNGUEZ ROCA, Luis J. Presentación al dossier Puerto y ciudad. Revista Transporte y Territorio. 2015, n. 12.

FERRER, Aldo, La economía argentina. Desde sus orígenes hasta principios del siglo XXI. Buenos Aires: Fondo de Cultura Económica, 2004. 
FRADKLIN, Raúl y GARAVAGLIA, Juan Carlos. La Argentina Colonial. El Río de la Plata entre los siglos XVII y XIX. Buenos Aires: Siglo XXI, 2009.

FÚRLONG, Guillermo. Nacimiento y desarrollo de la filosofía en el Río de la Plata, 1536-1810. Buenos Aires: Kraft, 1952.

GALLO, Klaus y BATTICUORE, Graciela. Ideas, literatura y opinión pública. En: TERNAVASIO, Marcela (dir.). Historia de la provincia de buenos Aires. Tomo 3: De la organización provincial a la federalización de Buenos Aires (1821-2880). Buenos Aires: Edhasa, 2013.

GARRIGA, Carlos. Orden jurídico y poder político en antiguo régimen: la tradición jurisdiccional. En: GARRIGA, Carlos y LORENTE SARIÑENA, Marta. Cádiz 1812. La constitución jurisdiccional. Madrid: CEPC, 2007.

GIANELLO, Leoncio. Historia de Entre Ríos, 1520-1910. Paraná: Ministerio de Educación, 1951.

GOLDMAN, Noemí, y PASINO, Alejandra. Opinión pública. En: GOLDMAN, Noemí (ed.). Lenguaje y revolución: conceptos políticos clave en el Río de la Plata, 1780-1850. Buenos Aires: Prometeo, 2008.

GOLDMAN, Noemí. Mariano Moreno. De reformista a insurgente. Buenos Aires: Edhasa, 2016.

GONZÁLEZ LEBRERO, Rodolfo. Promoting enlightment and virtues: The Colegio de la Unión del Sud, 1818-1823. En: GARAVAGLIA, Juan Carlos y PRO RUIZ, Juan (eds.). Latin American Bureaucreacy and the State Building Process (17801860). Cambridge Scholars Publishing Newcatle, 2013, pp. 302-346.

HALPERÍN DONGHI, Tulio. Guerra y finanzas en los orígenes del Estado argentino (1791-1850). Buenos Aires: Editorial de Belgrano, 1982.

HALPERÍN DONGHI, Tulio. Historia de la Universidad de Buenos Aires. Buenos Aires: Eudeba, 1962.

HALPERÍN DONGHI, Tulio. Revolución y guerra: Formación de una élite dirigente en la Argentina criolla. Buenos Aires: Siglo XXI, 1972.

HERRERO, Fabián. La revolución dentro de la revolución. En: HERRERO, Fabián (comp.). Revolución. Política e ideas en el Río de la Plata durante la década de 1810. Rosario: Prohistoria, 2010.

HERRERO, Fabián. Un golpe de Estado en Buenos Aires durante octubre de 1820. Anuario IEHS. 2003, n. 18.

HOYLE, Brian. The port-city interface: Trends, problems and examples. Geoforum. 1989, vol. 20, n. 20, pp. 429-436. 
JUMAR, Fernando y BIANGARDI, Nicolás. Espacio económico y territorialidad en el Río de la Plata del siglo XVIII. En: RICHARD-JORBA, Rodolfo y BONAUDO, Marta (comps.). Historia Regional. Enfoques y articulaciones para complejizar una historia nacional. La Plata: Universidad Nacional de La Plata, 2016, p. 78.

JUMAR, Fernando [et al.]. El comercio ultramarino y la economía local en el complejo portuario rioplatense. Siglo XVIII. Anuario del IEHS. 2006, n. XXI.

LAVALLÉ, Bernard. El mercader y el marqués. Las luchas de poder en el Cuzco (1700-173). Lima: Banco Central de Reserva del Perú, 1988.

LÉRTORA MENDOZA, Celina Ana. La enseñanza de la filosofía en tiempos de la colonia. Buenos Aires: Fundación para la educación, la cultura y la ciencia, 1979.

LEVENE, Ricardo. Vida y escritos de Victorián de Villava. Publicación del Instituto de investigaciones históricas. 1946, n. 95.

LEVENE, Ricardo. Ensayo histórico sobre la Revolución de Mayo y Mariano Moreno. Buenos Aires: Facultad de Derecho y Ciencias Sociales, 1921.

LEVENE, Ricardo. La Academia de jurisprudencia de Buenos Aires y su labor en orden a los estudios de derecho patrio y la reforma de la legislación. Buenos Aires: Universidad de Buenos Aires, 1941.

MAZíN, Óscar. Gentes de saber en los virreinatos de Hispanoamérica (siglos XVI al XVIII. En: ALTAMIRANO, Carlos y MYERS, Jorge (coords.). Historia de los intelectuales en América Latina. Vol I: La ciudad letrada, de la conquista al modernismo. Buenos Aires: Katz, 2008, pp. 53-78.

MOUTOUKIAS, Zacarías. Contrabando y control colonial. Buenos Aires, el Atlántico y el espacio peruano en el siglo XVII. Buenos Aires: Centro Editor de América Latina, 1988, pp. 46 y ss.

MYERS, Jorge, El letrado patriota: los hombres de las letras hispanoamericanos en la encrucijada del colapso del imperio español en América. en: ALTAMIRANO, Carlos y MYERS, Jorge (coords.). Historia de los intelectuales en América Latina. Vol I: La ciudad letrada, de la conquista al modernismo. Buenos Aires: Katz, 2008, pp. 121-144.

PORTILLO VALDÉS, José María (comp.). La vida atlántica de Victorián de Villava. Madrid: Fundación Mapfre, 2009.

RAVIGNANI, Emilio. Historia constitucional de la República Argentina. Vol. 2. Buenos Aires: Peuser, 1927.

Registro oficial de la provincia de Buenos Aires. Buenos Aires, José Luis y Rossi, 1825. 
SALVADORES, Antonio. Real Colegio de San Carlos. En: Academia Nacional de la Historia. Historia de la Nación Argentina. Buenos Aires: El Ateneo, 1940.

SCHMIT, Roberto y DJENDEREDJIAN, Julio. Los límites de la gran empresa agraria en el nacimiento del capitalismo rioplatense. Una estancia entrerriana durante la primera mitad del siglo XIX. Anuario IEHS. 2011, vol. 25, pp. 395-414.

SEGRELLES, José Antonio. Los puertos, la mundialización de la economía y la ordenación del territorio, en: GeoUruguay. Revista Uruguaya de Geografía. 2000, vol. 4, pp. 117-137.

SERRANO, Sol. Universidad y nación. Chile siglo XIX. Santiago de Chile: Editorial Universitaria, 1993.

SOCOLOW, Susana. The Bureaucrats of Buenos Aires, 1769-1810: Amor Al Real Servicio. London: Duke University Press, 1987.

TANDETER, Enrique. Coacción y Mercado: la Minería de la Plata en el Potosí Colonial, 1692-1826. Buenos Aires: Sudamericana, 1992.

TAU ANZOÁTEGUI, Víctor. Formación del Estado Federal Argentino, 1829-1852: la intervención del gobierno de Buenos Aires en los asuntos nacionales. Buenos Aires: Editorial Perrot, 1965.

TERNAVASIO, Marcela. Gobernar la revolución. Poderes en disputa en el Río de la Plata (1810-1816). Buenos Aires: Siglo XXI, 2007.

THIBAUD, Clément. La Academia Carolina y la independencia de América. Los abogados de Chuquisaca (1776 - 1809). Sucre: Editorial Charcas; Fundación Cultural del Banco Central de Bolivia; Archivo y Biblioteca Nacionales de Bolivia, 2010.

Universidad de Buenos Aires-Facultad de Filosofía y Letras. Documentos para la historia argentina. Tomo 13. Bueno Aires: Compañía Sud-Americana de Billetes de Banco, 1911.

UNZUÉ, Martín. Historia del origen de la Universidad de Buenos Aires (A propósito de su $190^{\circ}$ aniversario). Revista Iberoamericana de Educación Superior (RIES) [en línea]. 2012, vol. III, n. 8. Disponible en $<$ http://www.scielo.org.mx/scielo.php?script=sci arttext\&pid=S200728722012000300004>.

URQUIZA ALMANDOZ, Óscar. Historia económica y social de Entre Ríos (16001854). Paraná: Banco Unido del Litoral, 1978.

VILAR, Pierre. Crecimiento económico y análisis histórico. En: VILAR, Pierre (dir.). Crecimiento y Desarrollo. Barcelona: Ariel, 1980. 
Ariel Alberto EIRIS. La trayectoria de Pedro José Agrelo a través de la circulación regional y la dinámica ciudad-puerto.

ZORRAQUÍN BECÚ, Ricardo. El federalismo argentino. Buenos Aires: Perrot, 1958.

ZORRAQUÍN BECÚ, Ricardo. Historia del derecho argentino. Tomo II (1810-1969). Buenos Aires: Editorial Perrot, 1966. 